\title{
CLINICAL STUDY OF PREGNANCY WITH HYPOTHYROIDISM AND ITS OUTCOME IN TERTIARY CARE HOSPITAL
}

\author{
Mohammed M. Z1, Chandrashekar $\mathrm{K}^{2}$
}

${ }^{1}$ Assistant Professor, Department of Medicine, Vijayanagara Institute of Medical Sciences, Bellary.

${ }^{2}$ Assistant Professor, Department of Obstetrics \& Gynaecology, Vijayanagara Institute of Medical Sciences, Bellary.

ABSTRACT: AIM: To study the incidence of hypothyroidism in pregnancy and its effect on maternal and fetal outcome.

METHOD: Fifty pregnant women who delivered in VIMS Medical College Hospital, Bellary, during the study period of November 2013 till October 2014 were evaluated for the study. TSH screening was done in first antenatal visit. Those patients with TSH levels $>2.5 \mathrm{miu} / \mathrm{L}$ in first trimester and $>3 \mathrm{miu} / \mathrm{l}$ in second and third trimester were supplemented with thyroid hormone. The proportion of hypothyroidism in pregnancy during the study period was calculated. Their obstetric outcome in terms of abortion, anemia, preterm delivery, pre-eclampsia and perinatal outcome in terms of low birth weight.

RESULTS: The incidence of hypothyroidism in pregnancy was $6.3 \%$. Maternal complications included anemia 18\%, pre-eclampsia 16\%, GDM-4\%, PPH 6\%, preterm delivery $4 \%$ and abruptio placentae $2 \%$.

CONCLUSION: The incidence of hypothyroidism in pregnancy is found to be very high. By timely screening and supplementing thyroxin in patients with hypothyroidism maternal and fetal complication can be prevented, so routine screening of thyroid dysfunction is recommended in pregnancy.

KEYWORDS: Hypothyroidism Incidence, Pregnancy, Maternal Outcome.

HOW TO CITE THIS ARTICLE: Mohammed M. Z, Chandrashekar K. "Clinical Study of Pregnancy with Hypothyroidism and its Outcome in Tertiary Care Hospital." Journal of Evolution of Medical and Dental Sciences 2015; Vol. 4, Issue 94, November 23; Page: 15927-15929, DOI: 10.14260/jemds/2015/2319.

INTRODUCTION: Hypothyroidism during pregnancy is deleterious to both mother and child. Children born to untreated or under treated mothers have profound effect on future intellectual development. ${ }^{1}$ Pregnancy has a profound impact on the thyroid gland and thyroid function. During pregnancy, the thyroid gland may enlarge by $10 \%$ in countries where iodine sources are sufficient and to a greater extent in iodine-poor countries. ${ }^{2}$ Production of thyroid hormones and iodine requirement each increases by approximately $50 \%$ during pregnancy. ${ }^{3}$

Thyroid disorders constitute one of the most common endocrine disorders in pregnancy. ${ }^{4}$ Subclinical hypothyroidism describe those patients with high TSH and normal thyroxin concentration with no specific symptoms or signs of thyroid dysfunction. Subclinical hypothyroidism affects $5 \%$ of population. ${ }^{5}$ Casey et al. 6 in their study identified $2.3 \%$ of subclinical hypothyroidism and identified a trend towards increased preterm delivery NICU admission and neonatal RDS among the newborns of women with subclinical hypothyroidism.

Women with both overt and subclinical hypothyroidism are at increased risk of pregnancy related complication such as abortions, preeclampsia, preterm labour, placental abruption and PPH. Fetal complication include low birth weight babies, prematurity, fetal or neonatal hypothyroidism, growth retardation, still birth, neonatal hyperbilirubinemia and increased perinatal mortality.

Financial or Other, Competing Interest: None.

Submission 01-11-2015, Peer Review 02-11-2015,

Acceptance 13-11-2015, Published 20-11-2015.

Corresponding Author:

Dr. Chandrashekar $K$,

M. V. Nagar, $2^{\text {nd }}$ Cross (Left),

Kappagal Road,

Ballari-583101.

E-mail: shekarinvims7@gmail.com

DOI:10.14260/jemds/2015/2319.
MATERIAL AND METHODS: The study was conducted in the Department of Obstetrics and Gynecology and Medicine, VIMS Medical College, Bellary, between November 2013 till October 2014. A total of 50 patients who delivered in VIMS Medical College were evaluated for the effect of hypothyroidism in pregnancy. All these patients were diagnosed as hypothyroidism in the antenatal clinics and were treated with thyroid hormone.

INCLUSION CRITERIA: All patients with singleton delivery.

EXCLUSION CRITERIA: Multiple pregnancy, Pregestational Diabetes, Chronic Hypertension.

Apart from detailed history and examination TSH was tested in all patients enrolled in the study.

Reference range used in the study was based on guidelines of the American thyroid association $2011 .{ }^{7}$ for the diagnosis and management of thyroid disease during pregnancy and postpartum. According to the guidelines of trimester - specific reference ranges for TSH are not available in the laboratory. The following reference ranges are recommended: First trimester 0.1-2.5 micro IU/ml; second trimester 0.2-3 micro $\mathrm{IU} / \mathrm{|ml}$. The patients with hypothyroidism were treated and followed up till the termination of pregnancy.

TSH was repeated after 6 wks. and drug dosages titrated accordingly. Maternal outcome like abortion, preterm delivery, pre-eclampsia and fetal outcome like LBW were evaluated.

\section{RESULTS:}

Total number of delivery - 787.

Number of hypothyroidism - 50 .

Incidence of hypothyroidism $=6.3$. 


\begin{tabular}{|c|c|}
\hline \multirow{2}{*}{ AGE DISTRIBUTION } & CASE (n-50) \\
\cline { 2 - 2 } & $\mathbf{\%}$ \\
\hline$<20$ & 3 \\
\hline $20-24$ & 9 \\
\hline $25-29$ & 24 \\
\hline $30-34$ & 11 \\
\hline $35-40$ & 3 \\
\hline \multicolumn{2}{|c|}{ Table 1: Age Distribution of the Study Population } \\
\hline
\end{tabular}

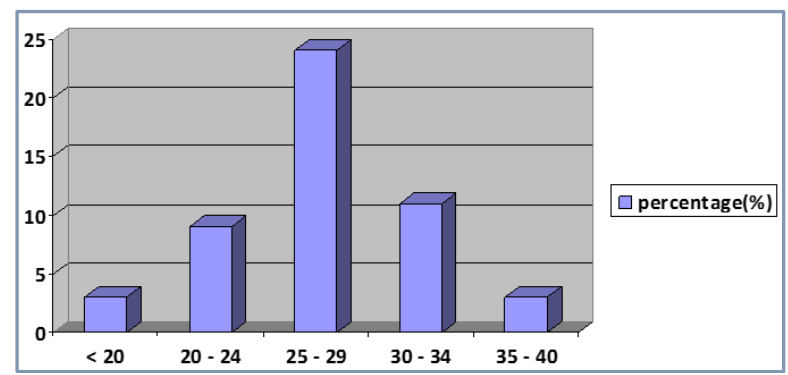

Chart. 1: Age Distribution

In the age group 25-29, there is increased incidence of hypothyroidism.

\begin{tabular}{|c|c|}
\hline Maternal Complications & Cases (50) \\
\hline Abortion & 1 \\
\hline Preterm delivary & 2 \\
\hline Pre-eclampsia & 8 \\
\hline Anemia & 9 \\
\hline PPH & 3 \\
\hline GDM & 2 \\
\hline Abruptio placenta & 1 \\
\hline \multicolumn{2}{|c|}{ Table 2: Maternal Complications } \\
\hline
\end{tabular}

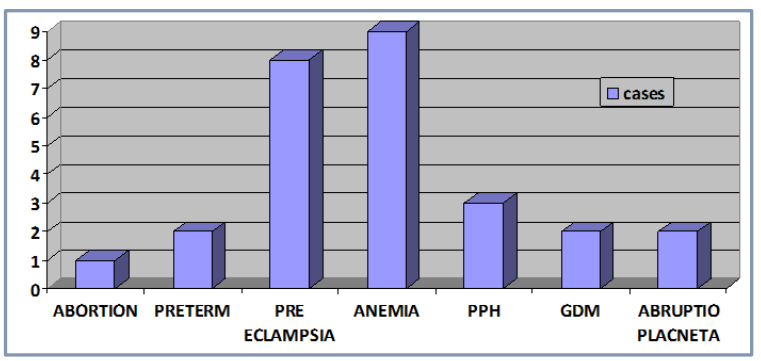

Chart. 2: Maternal Complications

In our study anemia form the most commonest condition followed by pre-eclampsia, PPH, preterm delivery, GDM and abruption placentae.

\begin{tabular}{|c|c|}
\hline Mode of Delivery & Cases (50) \\
\hline Preterm vaginal delivery & 2 \\
\hline FTND & 31 \\
\hline Forceps & 5 \\
\hline Vaccum & 4 \\
\hline LSCS & 8 \\
\hline \multicolumn{2}{|c|}{ Table 3: Mode of Delivery }
\end{tabular}

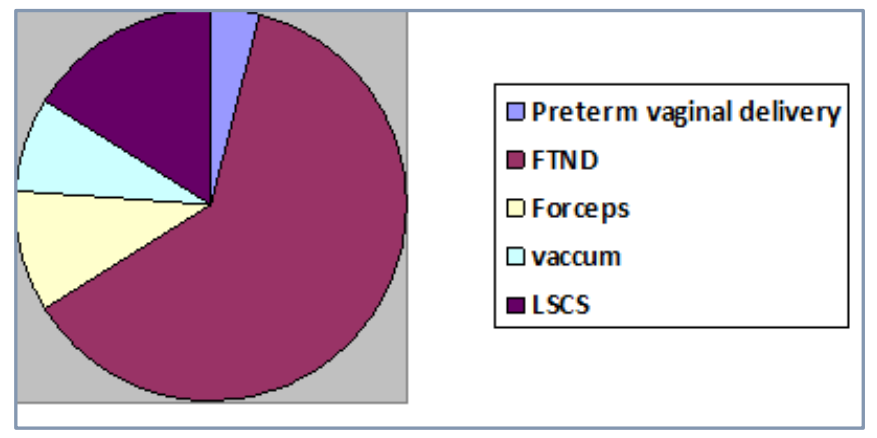

Chart. 3: Mode of Delivery

DISCUSSION: It is better to screen women early in pregnancy for thyroid dysfunction. They are common, treatable, and to some extent preventable condition which cause special risk for pregnancy and developing fetus. Screening for thyroid dysfunction is important because thyroid hormone status is directly related to fetal brain development. ${ }^{8}$

Incidence of hypothyroidism in our study is $6.3 \%$. Thus necessitating the need for thyroid dysfunction. Maternal complications are shown in Table 2. Mode of delivery as shown in Table 3.

Allanetal. ${ }^{9}$ showed that TSH levels greater than $6 \mathrm{mU} / \mathrm{L}$ were associated with higher frequency of still birth. Benhadietal. ${ }^{10}$ found that high maternal TSH levels were associated with an increased risk of pregnancy loss. Because TSH is inversely related to hCG levels. Women with low hCG levels are at a greater risk of childloss. Goel et al. ${ }^{11}$ reported a higher incidence of fetal distress in pregnancies complicated by maternal hypothyroidism.

Sahu et al. reported that the prevalence of overt and subclinical hypothyroidism in high-risk pregnant was $6.47 \%$ which is comparable to our study.

This study conclude that there is high prevalence of hypothyroidism. The majority being subclinical hypothyroidism. The maternal and fetal complication can be prevented by treating patients with thyroid hormone. Maternal complications like ANEMIA (18\%) and preeclampsia (16\%) are high in patients with hypothyroidism.

CONCLUSION: The incidence of hypothyroidism in pregnancy is found to be very high. By timely screening and supplementing thyroxin in patients with hypothyroidism maternal and fetal complication can be prevented, so routine screening of thyroid dysfunction is recommended in pregnancy. Maternal complication like gestational diabetes and preeclampsia are high. So routine screening. 


\section{REFERENCES:}

1. Stagnaro-Green A, Abalovich M, Alexander E, Azizi F, Mestman J, Negro R, et al. Guidelines of the American Thyroid Association for the Diagnosis and Management of Thyroid Disease During Pregnancy and Postpartum. Thyroid 2011; 21:1081-125.

2. Van Raaij JM, Vermaat-Miedema SH, Schonk CM, Peek ME, Hautvast JG. Energy requirements of pregnancy in The Netherlands. Lancet 1987; 2:953-5.

3. Glinoer D. The regulation of thyroid function in pregnancy: Pathways of endocrine adaptation from physiology to pathology. Endocr Rev 1997; 18:404-33.

4. Abalovich M. Amino N, Barbour LA et al. Management of thyroid dysfunction during pregnancy and postpartum, an endocrine society clinical practice guideline. J clin Endocrinol Metab 2007: 92 (8): 1-47.

5. James Steer, Weiner, Gonik, Crowther, Robson. High Risk Pregnancy Management Option (4th edition).St louis: Saunders, 2011.
6. Casey BM, Dashe JS, Wells CE, et al. Subclinical Hypothyroidism and Pregnancy Outcomes. Obstetrics Gynecology 2005: 105: 239-245.

7. Stagnaro- Green A, Abalovich $M$ Alexander $E$ et al. Guidelines of the American Thyroid Association for the diagnosis and management of thyroid disease during pregnancy hypothyroidism in pregnancy and postpartum. Thyroid 2011: 21 (10): 1081-125.

8. Agmani Sangita Nangia, Agarwal Deepa. The Journal of Obstetrics and Gynecology of India (March- April 2014) 64 (2): 105-110.

9. Allan WC, Haddow JE, Palomaki GE et al. Maternal thyroid deficiency and pregnancy complications: Implications for population screening. J Med Screen. 2000: 7: 127-130.

10. Benhadi N Wiersinga WM, Reitsma JB, et al. Higher maternal TSH levels in pregnancy are associated with an increased risk for miscarriage, fetal or neonatal death. Eur J Endocrinol. 2009; 160 (6) 985-91.

11. Goel P Radotra a Devi K, et al. Maternal and perinatal outcome in pregnancy with hypothyroidism. Indian J Med Sci 2005; 59: 116-7. 